\title{
SARS-CoV-2: Virology and Drug Repurposing Approaches
}

\author{
Ratika Rahmasari ${ }^{1 *}$, Heri Setiawan ${ }^{1}$, Rezi Riadhi Syahdi', Ayun Arifianti', Marina Ika \\ Irianti $^{1}$, Rani Sauriasari ${ }^{1}$, Juliann Nzembi Makau ${ }^{2}$, Muhareva Raekiansyah ${ }^{3}$ \\ ${ }^{1}$ Faculty of Pharmacy, Universitas Indonesia, Depok, Indonesia \\ ${ }^{2}$ Kenya Research Station, Institute of Tropical Medicine, Nagasaki University, Nagasaki, Japan \\ ${ }^{3} \mathrm{PT}$ Sciencewerke Indonesia
}

\begin{abstract}
An emerging coronavirus, SARS-CoV-2, is the causative agent for the ongoing pandemic of coronavirus disease 2019 (COVID-19), which has caused a worldwide social and economic disruption. Currently, no antiviral drugs with proven clinical efficacy, or vaccines for its prevention. Therefore, to combat the pandemic of this novel coronavirus, new effective treatments are urgently needed. In the process of traditional drug development, developing new drugs from scratch is a timeconsuming process, requires high-investment, and is a high-risk process, which is impractical to face the immediate global challenge of the SARS-CoV-2 pandemic. Drug repurposing strategy is one of the effective ways to quickly find a therapeutic agent for COVID-19 Existing medicines, which already have been tested and proven safe in humans might work for COVID-19 offering a potentially faster approach for the disease management. Here, we review $h$ the latest research progress in epidemiology, viral genome, and life cycles of SARS-CoV-2. Further, we describe and discuss some promising drugs repurposed to target SARS-CoV-2 that are being evaluated in clinical trials.
\end{abstract}

Keywords: drug repurposing; epidemiology; life cycles; SARS-CoV-2

*corresponding author

Email: ratika.rahmasari@farmasi.ui.ac.id

\section{INTRODUCTION}

Viral diseases continue to emerge and represent a serious public health problem. In the last two decades, several viral epidemics have been recorded, including the severe acute respiratory syndrome coronavirus (SARS-CoV) from 2002 to 2003, swine flu (H1N1 influenza) in 2009 and Middle East respiratory syndrome coronavirus (MERS-CoV) that emerged for the first time in Saudi Arabia in 2012. SARS-CoV that provoked a large-scale outbreak was reported for the first time in China, with approximately 8,000 cases and 800 deaths across 37 countries (Peiris et al., 2003), and MERS-CoV had about 2,500 confirmed cases with more than 800 deaths (Zaki et al., 2012). Meanwhile, H1N1 influenza was estimated to cause $150,000-600,000$ people died worldwide during the first year the virus circulated. At the end of 2019, a novel coronavirus, called SAR-CoV-2, emerged in Wuhan, China, and spread within months to other regions. All the end of January 2020, the WHO had declared the disease as a public health emergency of international concern, and on March $11^{\text {th }}, 2020$, WHO formally recognized it as a global pandemic.

The latest and an ongoing SARS- CoV- 2 outbreak, by surprise, has triggered a humanitarian crisis. The efficient human to human transmission of SARSCoV-2, through sneezing, coughing, droplet, aerosol, and followed by human traveling, are the main factors of its global spread (Lofti et al., 2020; Rabaan et al.,
2020). At the time of this manuscript preparation, the virus has infected more than 16 million people with more than 600,000 death. Indonesia has reported more than 100,000 confirmed cases with 4,600 deaths related to the SARS-CoV-2, bringing it as one of the countries in Southeast Asia region hardest hit by the virus (Johns Hopkins Coronavirus Resource Center, 2020). The case fatality rate (CFR) of SARS-CoV-2 infection varies in each country. In Southeast Asia, again, Indonesia has the highest rate of CFR. Many factors have been sought to interfere with the fatality case variation, such as age distribution, healthcare condition, coinfection, and overlying health conditions. To be aware of, theelderly and people with an overlying condition such as cardiovascular disease, diabetes, respiratory disease, and cancer are more vulnerable to SARS-CoV-2. Even though CFR of SARS-CoV-2 was higher than influenza (de Wit et al., 2020; Fauci et al., 2020), it did not reflect the risk of death since the actual number of infections was unknown (Roser et al., 2020; Read et al., 2020).

\section{SARS-COV-2: ORIGIN AND VIROLOGY}

As suggested by epidemiological evidence, the SARSCoV-2 outbreak began from the city of Wuhan in Hubei Province of central China. It was thought that the Huanan seafood and live animal shopping center was to be one of the places where the novel virus from an unknown animal source might have crossed the species barrier to infect humans (Cascella et al., 2020). 
Coronavirus is a large family of viruses that are commonly found in people and many different species of animals, including cats, cattle, camels, and bats. The viruses cause illness ranging from the common cold to more severe diseases (Cascella et al., 2020; Walls et al., 2020). Coronaviruses are divided into four genera, including Alphacoronavirus $(\alpha-\mathrm{CoV})$, Betacoronavirus $(\beta-\mathrm{CoV})$, Deltacoronavirus $(\delta-\mathrm{CoV})$, and Gammacoronavirus $(\gamma-\mathrm{CoV})$. The $\alpha$ - and $\beta-\mathrm{CoV}$ are able to infect mammals, while $\gamma$ - and $\delta$-CoV tend to infect birds (Chan et al., 2013; Ye et al., 2020). SARS$\mathrm{CoV}-2$ belongs to the Betacoronavirus group, similar to SARS-CoV and MERS-CoV (Lu et al., 2020). Initially, the new virus was called $2019-\mathrm{nCoV}$, as it is similar to the one that caused the SARS outbreak (SARS-CoVs) with $82 \%$ genetically identical (Chan et al., 2020; Lu et al., 2020). Later, the International Committee on Taxonomy of Viruses (ICTV) permanently named it as SARS- CoV-2 virus and the causing disease as COVID-19. Even though the SARS-CoV-2 genome has high similarity with SARS-CoV, the Spike protein of SARS- CoV-2 is quite different from SARS-CoV. The presence of furin cleavage site in Spike protein of SARS-CoV-2 is responsible for its efficient spread from human to human compared to other beta viruses.

SARS-CoV-2 is enveloped and non-segmented positivestranded RNA virus of the order Nidovirales with a crown-like appearance under an electron microscope due to the presence of spike glycoproteins on the envelope. The genome bind to $\mathrm{N}$ protein and exist as a helical ribonucleoprotein complex. On the surface of the envelope, the homotrimer of $\mathrm{S}$ glycoprotein protrudes as spike glycoprotein, essential for entry into host cells. S glycoprotein consisted of S1 and S2 subunit. The S1 subunit binds with cell receptors, Angiotensinconverting enzyme 2 (ACE2), whereas the S2 subunit is responsible for the fusion process. The cleavage of $\mathrm{S}$ glycoprotein is mediated by host protease. Besides, the whole virus structure is 150 to $160 \mathrm{~nm}$ in size (Tortorici \& Veesler, 2019; Millet \& Whittaker, 2015; Zhou et al., 2020).

\section{GENOME AND SARS-COV-2 LIFE CYCLE}

The first complete genome of SARS-CoV-2, $29.9 \mathrm{~kb}$ in length, was revealed from Wuhan-Hu-1 coronavirus (WHCV), a strain of SARS-CoV-2 isolated from a COVID-19 pneumonia patient who was a worker in the Wuhan seafood market (Wu et al., 2020). The SARS- CoV-2 has been categorized as subgenus Sarbecovirus and is closely associated with two SARSlike CoVs (bat- SL-CoVZC45 and bat-SL-CoVZXC21) originating from the bat ( $\mathrm{Lu}$ et al., 2020). It has been known that SARS-CoV-2 is $80 \%$ homologous with SARS-CoV; some enzymes are even have more than
90\% similarity. The MERS-CoV and SARS-CoV-2 share $\sim 50 \%$ sequence similarity ( $\mathrm{Lu}$ et al., 2020). Meanwhile, the SARS-CoV and SARS-CoV-2 has approximately $72 \%$ resemblance in the spike (S) protein, which is involved in the attachment of virus glycoprotein and host receptors (Zhang \& Holmes, 2020). The SARS-CoV-2 genome contain six open-reading frames (ORFs) and several extra genes, in which the amino acid sequences of replicase domains are more than $90 \%$ identical to SARS-CoV. The distinction between these two viruses is the spike ( $\mathrm{S}$ ) gene (as mentioned above); SARS$\mathrm{CoV}-2$ has a longer $\mathrm{S}$ genes than SARS-CoV. Another sequence similarity to SARS-CoV-2 was detected in bat coronavirus RNA- dependent RNA polymerase (BatCoV RaTG13), which represented more than 96\% identical sequence. Therefore, the SARS-CoV-2 might have originated in bats since both SARS-CoV-2 and BatCoV RaTG13 showed the closest phylogenetic relationship (Zhou et al., 2020).

From recent studies, it has been clearly shown that SARS- CoV-2 use ACE2 found in the lower respiratory tract of humans, as receptor - the same cellular entry receptor, as SARS-CoV (Zhou et al., 2020). SARSCoV-2 through the virion Spike-glycoprotein has a stronger binding affinity to ACE2 (Walls et al., 2020), resulting in a much higher incidence of human to human transmission and causing a global pandemic. To hijack the target cell, SARS-CoV-2 enters the cells via endosomal membrane fusion. The virion S-glycoprotein on the surface of the virus, first mediates attachment to the cellular receptor, ACE2, on the surface of human cells. Membrane fusion then occurr where the ACE2virus complex translocates to endosomes. Fusion activity is activated by cleavage of $\mathrm{S}$ protein by the endosomal acid proteases. After virion is taken up into endosomes, the viral genome RNA is released into the cytoplasm.

The SARS-CoV-2 genomic RNA encoded non-structural proteins have a critical role in viral RNA synthesis and structural proteins are necessary for virion assembly. First, the uncoated RNA is translated into viral replicase polyproteins, ppla, and $1 \mathrm{ab}$. By viral proteinase, ppla and $1 \mathrm{ab}$ polyproteins and then cleaved into small non-structural proteins to form a replicationtranscription complex (RTC) in a double-membrane vesicle. Continuously, RTC replicate and synthesize a nested set of subgenomic negative-strand RNAs on the plus-strand genome that serve as templates for mRNA synthesis, which encode accessory proteins and structural proteins. The full-length negative-strand template is made as a template for genomic RNA. Viral nucleocapsids are assembled from genomic RNA and N protein in the cytoplasm, which is followed by budding into the lumen of the ERGIC (endoplasmic reticulum (ER)-Golgi intermediate compartment. Lastly, the 
virion-containing vesicles are fused with the plasma membrane to release the virus from the cell through exocytosis (Astuti \& Ysrafil, 2020; Shereen et al., 2020).

Currently, no specific antiviral agent for SARS-CoV-2 has not been found. However, the knowledge of the SARS- COV-2 origin and replication cycle could help in recognition of potential drugs based on its possible inhibitory stage. The entry site, coating, proteolysis process, RNA dependent RNA polymerase, and viral ribonucleocapsid assembly are promising targets for drug repurposing.

\section{PATHOGENESIS}

From the cell's perspective, the SARS-CoV-2 disease is divided into three phases, which are asymptomatic phase (initial infection), upper, and conducting airway response, and progression to ARDS (Wu \& McGoogan, 2020). After the initial infection, SAR2-CoV-2 migrate down to the deeper respiratory tract. This migration triggers a robust immune response, such as cytokine production (Mason, 2020). In severe cases, it leads to alveolar damaged (Qian et al., 2020). About $80 \%$ of the infected patient show no symptom or mild symptom and do not progress to acute respiratory distress syndrome (ARDS). However, 20\% of infected patients develop severe diseases, with $2 \%$ fatality rate. The elderly, people with overlay disease, cardiovascular disease, and hypertension had a higher risk of ARDS progression because of their diminished or imbalanced immune response and reduced ability to repair the damaged epithelium (Mason, 2020; Porcheddu et al., 2020).

Even though the pathogenesis of COVID-19 is yet to be fully understood, the primary pathogenesis of SARSCoV-2 infection is associated with severe pneumonia, RNAemia, ground-glass opacity of lung, acute cardiac injury, and high level of cytokines and chemokines (Rothan \& Byrareddy, 2020). Regarding cytokine, it was observed that in the severe patient, the IL2, IL6, IL7, IL10, IP10, MCP1, MIP1 $\alpha$, and TNF $\alpha$ were higher and presumed to correlate with the disease severity (Huang et al., 2020; Zhou et al., 2020). For drug repurposing, the pathogenesis of SARS-CoV-2 is crucial in determining potential therapeutics, as discussed briefly in the last section.

\section{DRUG REPURPOSING FOR SARS-COV-2 INFECTION}

All efforts should be made, including to develop an effective therapy to manage the SARS-CoV-2 pandemic. Vaccine development, however, could require at least 12-18 months, and the typical timeline from hit finding to drug registration of an antiviral is more than ten years.
Drug repositioning of known drugs must be urgently sought to meet the emerging issues of COVID-19. The repositioning of drugs has become a popular strategy in recent years. Compared to traditional drug development strategies, the strategy is efficient, economical, and involves less risk (Agrawal, 2015). This approach could significantly accelerate the development and deployment of potential therapies for COVID-19 treatment.

There are many investigational programs, and clinical trials have been initiated to identify an effective treatment targeting SARS-CoV-2. Clinical trials using repurposed clinical-stage or approved drugs have been under investigation for treating COVID-19 patients. These drugs include; hydroxychloroquine, lopinavir/ ritonavir, and remdesivir. Some other drugs also being investigated. At the time of writing this article, those medications are an experimental stage and had not been licensed or approved to treat SARS-CoV-2 infection.

\section{REMDESIVIR}

Synthesized and developed by Gilead Sciences in 2017, remdesivir (GS-5734) was initially developed as a treatment for Ebola virus infection. It is a broad-spectrum class of viral RNA-dependent RNA polymerases $(\mathrm{RdRp})$ inhibitors against several RNA viruses. Remdesivir has shown extensive antiviral activity, in vitro, against a diverse panel of RNA viruses not only Ebola virus, but also against Marburg, MERSCoV, SARS-CoV, Respiratory syncytial virus, Nipah and Hendra virus (Lo et al., 2017; Sheahan et al., 2017; Warren et al., 2016). In the viral life cycle, viral RdRp has a vital function in viral RNA synthesis. Due to high sequence, structural conservation, and lack of host homolog, RdRp presented an attractive target for inhibition of several RNA virus infection, including SARS-CoV-2.

Remdesivir is a prodrug of 1'-cyano-substituted adenosine nucleotide analog (NA). During disposition into the cell target, the prodrugs are metabolized to the active drug in the triphosphate form $\left(5^{\prime}-\mathrm{TP}\right)$. The active form NAs (GS-441524) is a competitive substrate for endogenous nucleotides incorporation into viral RNA by the RdRp, accounting for the antiviral effect. The mechanism of remdesivir's antiviral activity is likely through premature termination of viral RNA transcription by; first, NA incorporation might cause termination of RNA synthesis. This action could be either obligate, i.e., the analog lacks a 3'-OH required for RNA chain extension, or non-obligate, i.e., the analog perturbs the structure of product RNA enough to stop further synthesis by the polymerase. The second mode of action exist without termination of RNA synthesis, it possibly over high-number of incorporated NAs into the nascent RNA. The high incorporation of NAs result in 
unrecognized RNA as normal Watson-Crick nucleobases during the following rounds of RNA synthesis from the NAs-containing template, which ultimately lead to lethal mutagenesis caused by non-viable genomes (Gordon et al., 2020).

In non-human primate models, remdesivir had shown an extensive antiviral activity and an effective treatment of lethal viruses such as Ebola and Nipah infections (Lo et al., 2017). Remdesivir decreased lung virus titers significantly with improvements in pulmonary function in the SARS-mouse model when administered one day after the onset of the disease (Sheahan et al., 2020). Meanwhile, in a rhesus monkey model infected with MERS-CoV, a treatment of remdesivir 24 hours before an infection could completely prevent symptoms caused by MERS-CoV, strongly inhibited viral replications in the respiratory tract, and prevented the formation of pulmonary lesions (de Wit et al., 2020; Sheahan et al., 2017; Sheahan et al., 2020). In the macaque model of SARS-CoV-2 infection, early remdesivir treatment showed an extensive reduction in pulmonary damage and virus titer in bronchoalveolar lavages (Williamson et al., 2020). Further, a placebo-controlled randomized trial of remdesivir in 237 patients with severe SARS-CoV-2 infection manifestation showed that earlier treatment with remdesivir reduced the time of clinical improvement (Wang et al., 2020). Based on animal and limited clinical trial researches, the timing of remdesivir intervention was critical. Thus, a combination of remdesivir, together with the anti-inflammatory drug for a further clinical trial, was suggested (Wang et al., 2020). By the time this article was prepared, remdesivir had been advanced to a controlled-clinical trial on the United States and other international sites, in combination with baricitinib (antiinflammatory drug, explained on other potential drugs) for SARS-CoV-2 infection. The current clinical study included more than 1000 patients (National Institutes of Health, 2020).

\section{CHLOROQUINE AND HYDROXYCHLOROQUINE}

Chloroquine and hydroxychloroquine has been used to inhibit the growth of many different viruses, including influenza A H5N1, human coronavirus OC43, and the SARS coronavirus (Touret \& de Lamballerie, 2020). Chloroquine exerts its antiviral activity by increasing the $\mathrm{pH}$ of the cellular organelles, which block virion fusion and uncoating. It also inhibited viral entry by glycosylation of the cellular receptor of SARS-CoV (Liu et al., 2020). Chloroquine (N4-(7-Chloro-4-quinolinyl)N1,N1-diethyl-1,4-pentanediamine) were generally safe with a mild-transient side effect. However, chloroquine had a narrow therapeutic index, which had been associated with a life-threatening cardiovascular disorder. The use of chloroquine has been widely indicated for the prevention and treatment of Plasmodium infection (malaria). Hydroxychloroquine (2-[4-[(7-chloroquinolin-4-yl) amino]pentyl-ethylamino]ethanol) was a derivate of chloroquine, synthesized by the introduction of a hydroxyl group into chloroquine. It showed less toxicity in animals, and therefore, it might be a better drug choice than chloroquine. Since hydroxychloroquine is a derivate of chloroquine, it was a straightforward candidate for drug repurposing to treat the $2019-n C o V$ infection.

In early 2020, Wang and the team showed that chloroquine (diphosphate salt) was highly effective at the entry stage of the virus infection, as well as at the post-entry stage (Wang et al., 2020). Chloroquine showed half-maximal effective concentration $\left(\mathrm{EC}_{50}\right) 1.13 \mu \mathrm{M}$, half-cytotoxic concentration $\left(\mathrm{CC}_{50}\right)>100 \mu \mathrm{M}$, and selectivity index $\left(\mathrm{SI}=\mathrm{CC}_{50} / \mathrm{EC}_{50}\right)>88.50$. Compared to remdesivir, which showed $\mathrm{EC}_{50}=0.77 \mu \mathrm{M}, \mathrm{CC}_{50}>100$, and $\mathrm{SI}>129.87 \mu \mathrm{M}$, chloroquine had slightly lower potential against SARsCoV-2. However, chloroquine has a better safety record, higher availability, and lesser cost than remdesivir. Therefore, in terms of safety and access, chloroquine appeared to be a drug of choice (Liu et al., 2020). Afterward, several clinical trials had been quickly followed to test the efficacy and safety of chloroquine or hydroxychloroquine in the treatment of pneumonia caused by SARs-CoV-2 infection (Gao et al., 2020). The result of the trials which included more than 100 patients was that chloroquine phosphate significantly inhibited exacerbation of pneumonia, improved lung imaging, promoted negative virus conversion, and shortened the disease course compared to control treatment. Based on these findings, by February 15th, 2020, the National Health Commission of the People's Republic of China recommended chloroquine phosphate for the treatment of pneumonia caused by SARs-CoV-2 infection.

On the other hand, two clinical trials conducted by Gautret and his team (2020) supported the evidence that hydroxychloroquine was an effective medication in reducing nasopharyngeal viral load in COVID-19 patients, especially for the non-critical condition. The first was a prospective an open-label non-randomized trial that included 20 patients in a single treatment arm (hydroxychloroquine alone, $\mathrm{n}=14$, or with azithromycin, $\mathrm{n}=6$ ) and 16 patients as a control group. It was reported that on the sixth-day of post-inclusion, $70 \%$ of hydroxychloroquine-treated patients were virologically cured comparing with $12.5 \%$ in the control group. A combination with azithromycin increased the effectivity of viral load reduction (Gautret et al., 2020). The second trial was a prospective observational study that included more extensive subject as much of 80 patients. It showed that the combination of hydroxychloroquine and azithromycin resulted in a rapid fall of nasopharyngeal viral load, with $93 \%$ on day eighth. Patients were also 
quickly discharged from the infectious unit with an average length of stay of five days (Gautret et al., 2020). However, the aforementioned remarkable findings in the clinical trial of hydroxychloroquine had several substantial limitations. The results from clinical trials registered in the Chinese Clinical Trial Registry were announced, but without any data provided. It made more difficulties to get a firm conclusion (Touret \& de Lamballerie 2020). Subsequent clinical trials by Philippe Goutret had not included critically ill patients as the primary concern of high mortality rate of COVID-19, small cohort, absence of randomization, no control arm in the second trials, poor inclusion and exclusion criteria, and PCR data gaps between control and treatment groups (Kim et al., 2020; Taccone et al., 2020). Furthermore, hydroxychloroquine alone or in combination with azithromycin showed no clinical benefit in severely COVID-19 patients and for those requiring oxygen (Mahévas et al., 2020; Molina et al., 2020).

To answer the doubt on hydroxychloroquine use for COVID-19, Geleris and team (2020) conducted observational study in New York-Presbyterian Hospital (NYP)-Columbia University Irving Medical Center (CUIMC). This study included 1376 patients, 811 $(58.9 \%)$ of which received hydroxychloroquine, the median follow-up was of 22.5 days, and 346 patients (25.1\%) developed primary end-point which are intubation or death. Cox proportional-hazards regression analysis result showed that there was no significant association between hydroxychloroquine use and intubation or death (hazard ratio, 1.04, 95\% confidence interval, 0.82 to 1.32 ) (Geleris et al., 2020). A clinical trial by Boulware (2020), randomized, double-blind, and controlled by placebo, strengthen the result of the above study. In this study, the efficacy of hydroxychloroquine for postexposure prophylaxis was tested. As much as 821 participants were enrolled, $87.6 \%$ of which were reported high-risk contact with COVID-19 confirmed subject. $11.8 \%$ of the participant receiving hydroxychloroquine developed illness or laboratory confirmation of COVID-19 within 14 days, whereas the participant of the placebo group was $14.3 \%$ confirmed COVID-19. There was no significant difference between groups (Boulware et al., 2020). From these two clinical studies, we may conclude that hydroxychloroquine is not a drug of choice for COVID-19.

\section{LOPINAVIR/RITONAVIR}

Lopinavir and ritonavir are antiretroviral (ARV) drugs and initially developed as HIV-1 medications. Both are structurally related and belong to the peptidomimetic protease inhibitors (PIs) drug class. PIs inhibited essential viral protein production; thus, immature virions incapable of further infection process would be produced
(Cameron et al., 1999). Lopinavir and Ritonavir (brand name: Norvir) was developed by Abbott Laboratories (Now: AbbVie) and approved by the FDA in 2000 and 1996, respectively. Although it was initially developed as an independent antiviral agent, ritonavir co-administered with other protease inhibitors showed advantageous properties. Ritonavir inhibiting cytochrome P450 3A4 and prevented the other PIs metabolism, therefore boosted them (Lv et al., 2015). Lopinavir and ritonavir also had been used in a combination (code: LPV/r), under the brand name Kaletra (Mangum \& Graham, 2001).

$\mathrm{LPV} / \mathrm{r}$ is currently one of the four treatment options that are studied in "Solidarity" international clinical trials organized by the World Health Organization to combat COVID-19 (WHO, 2020). LPV/r was used in the previous SARS and MERS outbreak. Therefore, it was suggested that it could be considered as one of the potential therapeutic strategies (Yao et al., 2020). The rationale of the LPV/r used in COVID-19 was that both anti-HIV drugs were initially purposed to inhibit 3C like proteases $\left(3 \mathrm{CL}^{\mathrm{pro}}\right.$ ) of SARS CoV and MERS (Zumla et al., 2016). SARS-CoV-2 proteinase is an attractive drug target and highly conserved, compared to SARS-CoV with $96.1 \%$ sequence similarities. However, whether HIV protease inhibitors could effectively target SARS $\mathrm{CoV} 3 \mathrm{CL}^{\text {pro }}$ is still unclear and debatable, because in fact that these two enzymes came from two different families. HIV protease is from the aspartic protease family, and SARS-CoV-2 CL ${ }^{\text {pro }}$ is a member of the cysteine protease family (Nutho et al., 2020).

Many clinical studies have been done in a short time and on a small scale for LPV/r effectiveness on COVID-19 patients, and the results are still limited or inconclusive (Tao et al., 2020). In a previous case study done to four patients, LPV/r was given and showed promising effects as initial therapy of COVID-19 (Wang et al., 2020). Another study also showed a positive effect of lopinavir on COVID-19 in 10 patients (Liu et al., 2020). However, a retrospective study that observed 134 novel coronavirus pneumonia showed that there was no significant difference between $\mathrm{LPV} / \mathrm{r}$ treated group $(n=52)$ and the control group $(n=48)$ (Chen et al., 2020; Yao et al. 2020). Because of the conflicting results, verification study is still needed to be done on a larger scale to justify whether the treatment with LPV/r is effective and beneficial for COVID-19 patients.

\section{OTHER POTENTIAL DRUGS}

Since drug repurposing mainly aim at shortening the time for drug discovery by using existing drugs, computational methods such as in silico and networkbased drug repurposing also became important as a quick screening tools. These methods identified potential 
drugs and drugs combination not only synthetic but also from a natural product (Hijikata et al., 2020; Wrapp et al. 2020; Wu et al., 2020). In addition, as mentioned previously, ACE2 as host receptor, 3C-like proteinase as processed enzyme of viral protein, and 2'-O-Ribose methyltransferase (nsp16) which important in viral RNA caps finalization were also potential targets for SARSCoV-2 drug repurposing (Hijikata et al., 2020; Wrapp et al., 2020).

Based on in silico screening of lisinopril, enalaprilat, and captopril, which are targeted the ACE as hypertension drug has been failed to interfere with the receptorbinding domain interaction with SARS-CoV-2 surface glycoprotein ACE2 (Hijikata et al., 2020). On the same research, carfilzomib, which is a proteasome inhibitor, showed promising affinity to SARs-CoV-2 3C-like proteinase. Similar to carfilzomib, a natural productderived drug, sinefugin, showed interaction with the conserved area of 2'-O-ribose methyltransferase. In addition, network proximity analysis pointed out that silvestrol, also derived from natural products, had demonstrated a potential binding activity to RNA helicase of SARS- CoV-2. Moreover, the combination of toremifene (a cancer drug) with emodin (rheum tanguticum-derived drug) is potentially used as a SARSCoV-2 inhibitor in multiple mechanisms (Zhou et al., 2020; Ho et al., 2007). However, further experiments are still needed to be done before going to a clinical trial.

Drug repurposing screening also performed based on SARS-CoV-2 pathogenesis information such as inflammatory response. To note, pro-inflammatory cytokines such as IL 6 could be a potential target for drug repurposing. However, there is the main concern that anti-inflammatory use might increase secondary infection risk and delay the elimination of SARSCoV-2. Other things, anti-inflammation medication targeted only specific inflammatory factors, thus might not effective in stopping cytokine storm in SARSCoV-2 patients (Zhang, 2020). As SARS-CoV-2 patient observation, the use of corticosteroids did not support the stop of lung injury (Russell et al., 2020). However, the use of tocilizumab, which target IL 6 receptors is suggested to have improved oxygenation and reduced the opacity lung lesion based on CT scan results and gave the light for further trial (Xu et al., 2020). Currently, a clinical trial of tocilizumab had registered (Zhang, 2020). In addition to tocilizumab, it is reported that baricitinid, a Janus kinase inhibitor, an inhibitor of cytokine-release, in a limited clinical study (24 patients) of its safety and efficacy improved the clinical and laboratory parameters on moderate COVID-19 patients compared to baseline (Cantini et al., 2020). Recently, a clinical trial on the combination of baricitinid together with remdesivir is ongoing.

\section{CONCLUDING REMARK}

In facing the pandemic caused by the new coronavirus, SARS-CoV-2, all global researchers are working and sharing the data regarding virus character and result of drug repurposing. Besides vaccine development and rapid diagnostic tools, virus characteristics and drugs screening hold essential roles in stopping the virus transmission. Even though some of the drugs discussed above have been applied for treating the patient, a further clinical trial is required to assess their efficacy and safety. A combination of antiviral, such as remdesivir and the anti-inflammatory drug, could be potential for COVID-19 treatment.

\section{CONFLICT OF INTEREST}

No conflict of interest to declare

\section{REFERENCES}

Agrawal, P. (2015). Advantages and Challenges in Drug Re-Profiling. Journal of Pharmacovigilance, S2: e002. 10.4172/2329-6887.S2-e002.

Astuti, I., \& Ysrafil. (2020). Severe acute respiratory syndrome coronavirus 2 (SARS-CoV-2): an overview of viral structure and host response. Diabetes \& Metabolic Syndrome, 14(4), 407-412.

Boulware, D. R., Pullen, M. F., Bangdiwala, A. S., Pastick, K. A., Lofgren, S. M., Okafor, E. C., Skipper, C. P., Nascene, A. A., Nicol, M. R., Abassi, M., Engen, N. W., Cheng, M. P., LaBar, D., Lother, S. A., MacKenzie, L. J., Drobot, G., Marten, N., Zarychanski, R., Kelly, L. E., Schwartz, I. S., ... Hullsiek, K. H. (2020). A Randomized Trial of Hydroxychloroquine as Postexposure Prophylaxis for Covid-19. The New England Journal of Medicine, NEJMoa2016638.

Cameron, D. W., Japour, A. J., Xu, Y., Hsu, A., Mellors, J., Farthing, C., Cohen, C., Poretz, D., Markowitz, M., Follansbee, S., Angel, J. B., McMahon, D., Ho, D., Devanarayan, V., Rode, R., Salgo, M., Kempf, D. J., Granneman, R., Leonard, J. M., \& Sun, E. (1999). Ritonavir and saquinavir combination therapy for the treatment of HIV infection. AIDS (London, England), 13(2), 213-224.

Cantini, F., Niccoli, L., Matarrese, D., Nicastri, E., Stobbione, P., \& Goletti, D. (2020). Baricitinib therapy in COVID-19: A pilot study on safety and clinical impact. The Journal of Infection, 81(2), 318-356.

Cascella, M., Rajnik, M., Cuomo, A., Dulebohn, S. C., \& Di Napoli, R. (2020). Features, Evaluation and 
Treatment Coronavirus (COVID-19). In StatPearls. StatPearls Publishing.

Chan, J. F., Kok, K. H., Zhu, Z., Chu, H., To, K. K., Yuan, S., \& Yuen, K. Y. (2020). Genomic characterization of the 2019 novel human-pathogenic coronavirus isolated from a patient with atypical pneumonia after visiting Wuhan. Emerging Microbes \& Infections, 9(1), 221-236.

Chan, J. F., To, K. K., Tse, H., Jin, D. Y., \& Yuen, K. Y. (2013). Interspecies transmission and emergence of novel viruses: lessons from bats and birds. Trends in Microbiology, 21(10), 544-555.

de Wit, E., Feldmann, F., Cronin, J., Jordan, R., Okumura, A., Thomas, T., Scott, D., Cihlar, T., \& Feldmann, H. (2020). Prophylactic and therapeutic remdesivir (GS5734) treatment in the rhesus macaque model of MERS$\mathrm{CoV}$ infection. Proceedings of the National Academy of Sciences of the United States of America, 117(12), 6771-6776.

de Wit, E., van Doremalen, N., Falzarano, D., \& Munster, V. J. (2016). SARS and MERS: recent insights into emerging coronaviruses. Nature Reviews Microbiology, 14(8), 523-534.

Fauci, A.S., Lane, H.C., \& Redfield, R.R. (2020). Covid19-navigating the uncharted. The New England Journal of Medicine, 382(13), 1268-1269.

Gao, J., Tian, Z., \& Yang, X. (2020). Breakthrough: Chloroquine phosphate has shown apparent efficacy in treatment of COVID-19 associated pneumonia in clinical studies. Bioscience Trends, 14(1), 72-73.

Gautret, P., Lagier, J. C., Parola, P., Hoang, V. T., Meddeb, L., Sevestre, J., Mailhe, M., Doudier, B., Aubry, C., Amrane, S., Seng, P., Hocquart, M., Eldin, C., Finance, J., Vieira, V. E., Tissot-Dupont, H. T., Honoré, S., Stein, A., Million, M., Colson, P., ... \& Raoult, D. (2020). Clinical and microbiological effect of a combination of hydroxychloroquine and azithromycin in 80 COVID-19 patients with at least a six-day follow up: A pilot observational study. Travel Medicine and Infectious Disease, 34, 101663.

Gautret, P., Lagier, J. C., Parola, P., Hoang, V. T., Meddeb, L., Mailhe, M., Doudier, B., Courjon, J., Giordanengo, V., Vieira, V. E., Tissot Dupont, H., Honoré, S., Colson, P., Chabrière, E., La Scola, B., Rolain, J. M., Brouqui, P., \& Raoult, D. (2020). Hydroxychloroquine and azithromycin as a treatment of COVID-19: results of an open-label non-randomized clinical trial. International Journal of Antimicrobial Agents, 56(1), 105949.
Geleris, J., Sun, Y., Platt, J., Zucker, J., Baldwin, M., Hripcsak, G., Labella, A., Manson, D. K., Kubin, C., Barr, R. G., Sobieszczyk, M. E., \& Schluger, N. W. (2020). Observational study of hydroxychloroquine in hospitalized patients with Covid-19. The New England Journal of Medicine, 382(25), 2411-2418.

Gordon, C. J., Tchesnokov, E. P., Feng, J. Y., Porter, D. P., \& Götte, M. (2020). The antiviral compound remdesivir potently inhibits RNA-dependent RNA polymerase from Middle East respiratory syndrome coronavirus. The Journal of Biological Chemistry, 295(15), 4773-4779.

Hijikata, A., Shionyu-Mitsuyama, C., Nakae, S., Shionyu, M., Ota, M., Kanaya, S., \& Shirai, T. (2020). Knowledge-based structural models of SARS-CoV-2 proteins and their complexes with potential drugs. FEBS Letters, 594(12), 1960-1973.

Ho, T. Y., Wu, S. L., Chen, J. C., Li, C. C., \& Hsiang, C. Y. (2007). Emodin blocks the SARS coronavirus spike protein and angiotensin-converting enzyme 2 interaction. Antiviral Research, 74(2), 92-101.

Huang, C., Wang, Y., Li, X., Ren, L., Zhao, J., Hu, Y., Zhang, L., Fan, G., Xu, J., Gu, X., Cheng, Z., Yu, T., Xia, J., Wei, Y., Wu, W., Xie, X., Yin, W., Li, H., Liu, M., Xiao, Y., Cao, B. (2020). Clinical features of patients infected with 2019 novel coronavirus in Wuhan, China. Lancet (London, England), 395(10223), 497-506.

Johns Hopkins Coronavirus Resource Center (CRC). (2020). COVID-19 Map. Retrieved from Johns Hopkins University \& Medicine website: https://coronavirus.jhu. edu/map.html.

Kim, A., Sparks, J. A., Liew, J. W., Putman, M. S., Berenbaum, F., Duarte-García, A., Graef, E. R., Korsten, P., Sattui, S. E., Sirotich, E., Ugarte-Gil, M. F., Webb, K., \& Grainger, R. (2020). A rush to judgment? rapid reporting and dissemination of results and its consequences regarding the use of hydroxychloroquine for COVID-19. Annals of Internal Medicine, 172(12), 819-821.

Liu, F., Xu, A., Zhang, Y., Xuan, W., Yan, T., Pan, K., Yu, W., \& Zhang, J. (2020). Patients of COVID-19 may benefit from sustained Lopinavir-combined regimen and the increase of Eosinophil may predict the outcome of COVID-19 progression. International Journal of Infectious Diseases, 95, 183-191.

Liu, J., Cao, R., Xu, M., Wang, X., Zhang, H., Hu, H., Li, Y., Hu, Z., Zhong, W., \& Wang, M. (2020). Hydroxychloroquine, a less toxic derivative of 
chloroquine, is effective in inhibiting SARS-CoV-2 infection in vitro. Cell discovery, 6, 16.

Lo, M. K., Jordan, R., Arvey, A., Sudhamsu, J., Shrivastava-Ranjan, P., Hotard, A. L., Flint, M., McMullan, L. K., Siegel, D., Clarke, M. O., Mackman, R. L., Hui, H. C., Perron, M., Ray, A. S., Lu, R., Zhao, X., Li, J., Niu, P., Yang, B., Wu, H., Wang, W., Song, H., Huang, B., Zhu, N., Bi, Y., Ma, X., Zhan, F., Wang, L., Hu, T., Zhou, H., Hu, Z., Zhou, W., Zhao, L., Chen, J., ... Tan, W. (2020). Genomic characterisation and epidemiology of 2019 novel coronavirus: implications for virus origins and receptor binding. Lancet (London, England), 395(10224), 565-574.

Lv, Z., Chu, Y., \& Wang, Y. (2015). HIV protease inhibitors: a review of molecular selectivity and toxicity. HIV/AIDS (Auckland, N.Z.), 7, 95-104.

Mahévas, M., Tran, V. T., Roumier, M., Chabrol, A., Paule, R., Guillaud, C., Fois, E., Lepeule, R., Szwebel, T. A., Lescure, F. X., Schlemmer, F., Matignon, M., Khellaf, M., Crickx, E., Terrier, B., Morbieu, C., Legendre, P., Dang, J., Schoindre, Y., Pawlotsky, J. M., ... CostedoatChalumeau, N. (2020). No evidence of clinical efficacy of hydroxychloroquine in patients hospitalized for COVID-19 infection with oxygen requirement: results of a study using routinely collected data to emulate a target trial. MedRxiv, PPR:PPR150909.

Mangum,E.M.,\& Graham,K.K.(2001).Lopinavir-Ritonavir: a new protease inhibitor. Pharmacotherapy, 21(11), 13521363.

Mason R. J. (2020). Pathogenesis of COVID-19 from a cell biology perspective. The European Respiratory Journal, 55(4), 2000607.

Millet, J. K., \& Whittaker, G. R. (2015). Host cell proteases: Critical determinants of coronavirus tropism and pathogenesis. Virus Research, 202, 120-134.

Molina, J. M., Delaugerre, C., Le Goff, J., Mela-Lima, B., Ponscarme, D., Goldwirt, L., \& de Castro, N. (2020). No evidence of rapid antiviral clearance or clinical benefit with the combination of hydroxychloroquine and azithromycin in patients with severe COVID-19 infection. Medecine et Maladies Infectieuses, 50(4), 384.

National Institutes of Health. (2020). NIH clinical trial testing antiviral remdesivir plus anti-inflammatory drug baricitinib for COVID-19 begins. Retrieved from National Institutes of Health website: https://www. nih.gov/news-events/news-releases/nih-clinical-trialtesting-antiviral-remdesivir-plus-anti-inflammatorydrug-baricitinib-covid-19-begins.
Nutho, B., Mahalapbutr, P., Hengphasatporn, K., Pattaranggoon, N. C., Simanon, N., Shigeta, Y., Hannongbua, S., \& Rungrotmongkol, T. (2020). Why are lopinavir and ritonavir effective against the newly emerged coronavirus 2019? atomistic insights into the inhibitory Mechanisms. Biochemistry, 59(18), 17691779 .

Peiris, J. S., Lai, S. T., Poon, L. L., Guan, Y., Yam, L. Y., Lim, W., Nicholls, J., Yee, W. K., Yan, W. W., Cheung, M. T., Cheng, V. C., Chan, K. H., Tsang, D. N., Yung, R. W., Ng, T. K., Yuen, K. Y., \& SARS study group (2003). Coronavirus as a possible cause of severe acute respiratory syndrome. Lancet (London, England), 361(9366), 1319-1325.

Porcheddu, R., Serra, C., Kelvin, D., Kelvin, N., \& Rubino, S. (2020). Similarity in Case Fatality Rates (CFR) of COVID-19/SARS-COV-2 in Italy and China. Journal of Infection in Developing Countries, 14(2), 125-128.

Qian, Z., Travanty, E. A., Oko, L., Edeen, K., Berglund, A., Wang, J., Ito, Y., Holmes, K. V., \& Mason, R. J. (2013). Innate immune response of human alveolar type II cells infected with severe acute respiratory syndromecoronavirus. American Journal of Respiratory Cell and Molecular Biology, 48(6), 742-748.

Rabaan, A. A., Al-Ahmed, S. H., Haque, S., Sah, R., Tiwari, R., Malik, Y. S., Dhama, K., Yatoo, M. I., Bonilla-Aldana, D. K., \& Rodriguez-Morales, A. J. (2020). SARS-CoV-2, SARS-CoV, and MERS-COV: A comparative overview. Le Infezioni in Medicina, 28(2), 174-184.

Read, J.M., Bridgen, J.R., Cummings, D.A., Ho, A., \& Jewell, C.P. (2020). Novel coronavirus 2019-nCoV: early estimation of epidemiological parameters and epidemic predictions. MedRxiv, PPR:PPR110039.

Roser, M., Ritchie, H., Ortiz-Ospina, E., \& Hassel J. (2020). Coronavirus Pandemic (COVID-19). Retrieved from Our World In Data website: https://ourworldindata. org/coronavirus.

Rothan, H. A., \& Byrareddy, S. N. (2020). The epidemiology and pathogenesis of coronavirus disease (COVID-19) outbreak. Journal of Autoimmunity, 109, 102433

Russell, C. D., Millar, J. E., \& Baillie, J. K. (2020). Clinical evidence does not support corticosteroid treatment for 2019-nCoV lung injury. Lancet (London, England), 395(10223), 473-475. 
Sheahan, T. P., Sims, A. C., Graham, R. L., Menachery, V. D., Gralinski, L. E., Case, J. B., Leist, S. R., Pyrc, K., Feng, J. Y., Trantcheva, I., Bannister, R., Park, Y., Babusis, D., Clarke, M. O., Mackman, R. L., Spahn, J. E., Palmiotti, C.A., Siegel, D., Ray, A. S., Cihlar, T., ... Baric, R. S. (2017). Broad-spectrum antiviral GS-5734 inhibits both epidemic and zoonotic coronaviruses. Science Translational Medicine, 9(396), eaal3653.

Sheahan, T. P., Sims, A. C., Leist, S. R., Schäfer, A., Won, J., Brown, A. J., Montgomery, S. A., Hogg, A., Babusis, D., Clarke, M. O., Spahn, J. E., Bauer, L., Sellers, S., Porter, D., Feng, J. Y., Cihlar, T., Jordan, R., Denison, M. R., \& Baric, R. S. (2020). Comparative therapeutic efficacy of remdesivir and combination lopinavir, ritonavir, and interferon beta against MERSCoV. Nature Communications, 11(1), 222.

Shereen, M., A., Khan, S., Kazmi, A., Bashir, N., \& Siddique, R. (2020). COVID-19 infection: origin, transmission and characteristics of human coronaviruses. Journal of Advanced Research, 24, 9198.

Taccone, F. S., Gorham, J., \& Vincent, J. L. (2020). Hydroxychloroquine in the management of critically ill patients with COVID-19: the need for an evidence base. The Lancet. Respiratory Medicine, 8(6), 539-541.

Tao, Y., Tang, L. V., \& Hu, Y. (2020). Treatments in the COVID-19 pandemic: an update on clinical trials. Expert Opinion on Emerging Drugs, 25(2), 81-88.

Tortorici, M. A., \& Veesler, D. (2019). Structural insights into coronavirus entry. Advances in Virus Research, 105, 93-116.

Touret, F., \& de Lamballerie, X. (2020). Of chloroquine and COVID-19. Antiviral Research, 177, 104762.

Walls, A. C., Park, Y. J., Tortorici, M. A., Wall, A., McGuire, A. T., \& Veesler, D. (2020). Structure, function, and antigenicity of the SARS-CoV-2 spike glycoprotein. Cell, 181(2), 281-292.e6.

Wang, M., Cao, R., Zhang, L., Yang, X., Liu, J., Xu, M., Shi, Z., Hu, Z., Zhong, W., \& Xiao, G. (2020). Remdesivir and chloroquine effectively inhibit the recently emerged novel coronavirus (2019-nCoV) in vitro. Cell Research, 30(3), 269-271.

Wang, Y., Zhang, D., Du, G., Du, R., Zhao, J., Jin, Y., Fu, S., Gao, L., Cheng, Z., Lu, Q., Hu, Y., Luo, G., Wang, K., Lu, Y., Li, H., Wang, S., Ruan, S., Yang, C., Mei, C., Wang, Y., ... Wang, C. (2020). Remdesivir in adults with severe COVID-19: a randomised, double-blind, placebo-controlled, multicentre trial. Lancet (London, England), 395(10236), 1569-1578.

Wang, Z., Chen, X., Lu, Y., Chen, F., \& Zhang, W. (2020). Clinical characteristics and therapeutic procedure for four cases with 2019 novel coronavirus pneumonia receiving combined Chinese and Western medicine treatment. Bioscience trends, 14(1), 64-68.

Warren, T. K., Jordan, R., Lo, M. K., Ray, A. S., Mackman, R. L., Soloveva, V., Siegel, D., Perron, M., Bannister, R., Hui, H. C., Larson, N., Strickley, R., Wells, J., Stuthman, K. S., Van Tongeren, S. A., Garza, N. L., Donnelly, G., Shurtleff, A. C., Retterer, C. J., Gharaibeh, D., ... \& Bavari, S. (2016). Therapeutic efficacy of the small molecule GS-5734 against Ebola virus in rhesus monkeys. Nature, 531(7594), 381-385.

Williamson, B. N., Feldmann, F., Schwarz, B., MeadeWhite, K., Porter, D. P., Schulz, J., van Doremalen, N., Leighton, I., Kwe Yinda, C., Pérez-Pérez, L., Okumura, A., Lovaglio, J., Hanley, P. W., Saturday, G., Bosio, C. M., Anzick, S., Barbian, K., Cihlar, T., Martens, C., Scott, D. P., ... de Wit, E. (2020). Clinical benefit of remdesivir in rhesus macaques infected with SARS-CoV-2. bioRxiv: the preprint server for biology, 2020.04.15.043166.

World Health Organization. (2020). "Solidarity" clinical trial for COVID-19 treatments. Retrieved from World Health Organization website: https:/www.who.int/ emergencies/diseases/novel-coronavirus-2019/globalresearch-on-novel-coronavirus-2019-ncov/solidarityclinical-trial-for-covid-19-treatments.

World Health Organization. (2020). Pneumonia of unknown cause - China. Retrieved from World Health Organization website: https://www.who.int/csr/don/05january-2020-pneumonia-of-unkown-cause-china/en/ Wrapp, D., Wang, N., Corbett, K. S., Goldsmith, J. A., Hsieh, C. L., Abiona, O., Graham, B. S., \& McLellan, J. S. (2020). Cryo-EM structure of the 2019-nCoV spike in the prefusion conformation. Science (New York, N.Y.), 367(6483), 1260-1263.

Wu, C., Liu, Y., Yang, Y., Zhang, P., Zhong, W., Wang, Y., Wang, Q., Xu, Y., Li, M., Li, X., Zheng, M., Chen, L., \& Li, H. (2020). Analysis of therapeutic targets for SARS-CoV-2 and discovery of potential drugs by computational methods. Acta Pharmaceutica Sinica. $B, 10(5), 766-788$.

Wu, Z., \& McGoogan, J. M. (2020). Characteristics of and important lessons from the coronavirus disease 2019 (COVID-19) outbreak in China: summary of a report of 72314 cases from the Chinese Center for Disease Control and Prevention. JAMA, 10.1001/jama.2020.2648 
Xu, X., Han, M., Li, T., Sun, W., Wang, D., Fu, B., Zhou, Y., Zheng, X., Yang, Y., Li, X., Zhang, X., Pan, A., \& Wei, H. (2020). Effective treatment of severe COVID-19 patients with tocilizumab. Proceedings of the National Academy of Sciences of the United States of America, 117(20), 10970-10975.

Yao, T. T., Qian, J. D., Zhu, W. Y., Wang, Y., \& Wang, G. Q. (2020). A systematic review of lopinavir therapy for SARS coronavirus and MERS coronavirus-A possible reference for coronavirus disease-19 treatment option. Journal of Medical Virology, 92(6), 556-563.

Ye, Z. W., Yuan, S., Yuen, K. S., Fung, S. Y., Chan, C. P., \& Jin, D. Y. (2020). Zoonotic origins of human coronaviruses. International Journal of Biological Sciences, 16(10), 1686-1697.

Zaki, A. M., van Boheemen, S., Bestebroer, T. M., Osterhaus, A. D., \& Fouchier, R. A. (2012). Isolation of a novel coronavirus from a man with pneumonia in Saudi Arabia. The New England Journal of Medicine, 367(19), 1814-1820.

Zhang, W., Zhao, Y., Zhang, F., Wang, Q., Li, T., Liu, Z., Wang, J., Qin, Y., Zhang, X., Yan, X., Zeng, X., \& Zhang, S. (2020). The use of anti-inflammatory drugs in the treatment of people with severe coronavirus disease 2019 (COVID-19): The Perspectives of clinical immunologists from China. Clinical Immunology (Orlando, Fla.), 214, 108393.
Zhang, Y. Z., \& Holmes, E. C. (2020). A Genomic Perspective on the Origin and Emergence of SARSCoV-2. Cell, 181(2), 223-227.

Zhou, F., Yu, T., Du, R., Fan, G., Liu, Y., Liu, Z., Xiang, J., Wang, Y., Song, B., Gu, X., Guan, L., Wei, Y., Li, H., Wu, X., Xu, J., Tu, S., Zhang, Y., Chen, H., \& Cao, B. (2020). Clinical course and risk factors for mortality of adult inpatients with COVID-19 in Wuhan, China: a retrospective cohort study. Lancet (London, England), 395(10229), 1054-1062.

Zhou, P., Yang, X. L., Wang, X. G., Hu, B., Zhang, L., Zhang, W., Si, H. R., Zhu, Y., Li, B., Huang, C. L., Chen, H. D., Chen, J., Luo, Y., Guo, H., Jiang, R. D., Liu, M. Q., Chen, Y., Shen, X. R., Wang, X., Zheng, X. S., .. \& Shi, Z. L. (2020). A pneumonia outbreak associated with a new coronavirus of probable bat origin. Nature, 579(7798), 270-273.

Zumla, A., Chan, J. F., Azhar, E. I., Hui, D. S., \& Yuen, K. Y. (2016). Coronaviruses - drug discovery and therapeutic options. Nature reviews. Drug Discovery, 15(5), 327347. 